\title{
INDICIOS DE DISPLASIA ÓSEA EN UN NEONATO: REPORTE DE UN CASO
}

EVIDENCE OF BONE DYSPLASIA IN A NEONATE: A CASE REPORT EVIDÊNCIAS DE DISPLASIA ÓSSEA EM RECÉM-NASCIDO: RELATO DE CASO

\section{INGRID MASSON PINTO, GABRIELA MESTANZA ROSERO, PRISCILLA NARANJO FIALLOS, ANDRÉS MANCERO MERINO, CRISTIAN CAMACHO MERCHÁN}

Universidad Católica de Santiago de Guayaquil; Guayaquil, Ecuador

Resumen

Las displasias óseas son patologías que presentan una alteración del tejido óseo y constituyen la causa más frecuente de retardo de crecimiento. Hasta la actualidad se han descrito aproximadamente 450 tipos de displasias óseas. Se documenta un caso de infante de sexo masculino de 42 días de nacido que presenta rasgos dismórficos compatibles con una displasia ósea. Se realizó el estudio por imágenes para demostrar los signos radiográficos característicos de la enfermedad cuyo resultado demostró acortamiento de las extremidades. La acondroplasia presenta signos típicos como talla baja, abombamiento frontal, mano en tridente y fémur arqueado, en el caso de la hipocondroplasia los hallazgos esqueléticos son similares pero en una presentación menos severa por lo que el diagnóstico es difícil en niños por debajo de los 3 años.

PALABRAS CLAVE: osteocondrodisplasia, acondroplasia, enanismo.

Abstract

Bone dysplasias are pathologies that present alteration of the bone tissue and constitute the most frequent cause of growth retardation. To the present, approximately 450 types of bone dysplasias have been described. We documented a case of a 42-day-old male infant with dysmorphic features compatible with bone dysplasia. The imaging study was performed to demonstrate radiographic characteristic signs of the disease, the result of which showed a shortening of the extremities. Achondroplasia presents typical signs such as short stature, frontal bulge, trident hand, and arched femur, in case of hypochondroplasia the skeletal findings are similar but in a less severe presentation, making the diagnosis difficult in children below 3 years.

KEYWORDS: osteochondrodysplasia achondroplasia, dwarfism.

Resumo

As displasias ósseas são patologias que apresentam alteração do tecido ósseo e constituem a causa mais frequente de retardo de crescimento. Até 0 momento, foram descritos aproximadamente 450 tipos de displasias ósseas. Documentamos um caso de um menino de 42 dias com características dismórficas compatíveis com displasia óssea. 0 estudo por imagem foi realizado para demonstrar os sinais radiográficos característicos da doença, cujo resultado mostrou encurtamento das extremidades. A acondroplasia apresenta sinais típicos como baixa estatura, protuberância frontal, mão tridente e fêmur arqueado. No caso da hipocondroplasia, os achados esqueléticos são semelhantes, mas em uma apresentação menos grave, dificultando o diagnóstico em crianças abaixo de 3 anos. anos.

PALAVRAS-CHAVE: osteocondrodisplasias, acondroplasia, nanismo. 
INTRODUCCIÓN

Las displasias esqueléticas u osteocondrodisplasias son un conjunto de alteraciones que afectan al desarrollo, crecimiento y homeostasis del tejido óseo. Se presentan en las etapas iniciales del desarrollo fetal y pueden ser de herencia autosómico dominante o recesivo dependiendo del tipo de displasia. La Sociedad Internacional de Displasias Esqueléticas en su última revisión del 2010, estableció 456 tipos distribuidos en 40 categorías en función a sus características bioquímicas, moleculares y radiológicas. ${ }^{1}$

La etiología es variada pero puede ser de origen extrínseco (enfermedad autoinmune materna, exposición a teratógenos, etc.) o intrínseco (70\% debido a alteraciones genéticas) ${ }^{2}$. La importancia de una detallada historia clínica junto con una resonancia magnética, tomografía, o en algunos casos análisis molecular, confirmarán el diagnóstico presuntivo.

Es común confundir los casos de hipocondroplasia con los de acondroplasia. Los distintos signos pueden pasar desapercibidos hasta llegar a la pubertad, o pueden presentarse en los primeros años de vida con una mínima alteración en la talla. ${ }^{3}$ Las dos entidades presentan una mutación en el gen FGFR3 (receptor 3 del factor de crecimiento de fibroblastos), lo que establece su similitud, pero con signos menos severos en la hipocondroplasia. La función normal del gen FGFR3 es ser un regulador negativo del crecimiento de los huesos, su mutación permite la activación continua de FGFR 3 provocando que haya menos diferenciación y más proliferación. ${ }^{4,5}$ Debido a la gran variedad de displasias, es necesario establecer diferenciales clínicos, radiológicos y moleculares.

Para confirmar la hipocondroplasia, es necesario realizar un seguimiento a partir de los 3 años de edad junto con un estudio molecular exhaustivo. El seguimiento se enfocará en la asociación o no de retraso mental y la medición de la talla acorde a su edad. Las características radiológicas de dicha displasia fueron descritas, aunque no hay signos radiológicos considerados patognomónicos. ${ }^{3}$ Lo que resalta la importancia de realizar un estudio molecular.

\section{CASO CLÍNICO}

Se reporta el caso de un infante masculino, de 42 días de vida, tercer hijo de una madre de 28 años y un padre de 34 años, ambos saludables y no consanguíneos. La madre se realizó 2 con- troles prenatales con respectivos ultrasonidos, en la semana 20 y 36, en la que se refirió que las mediciones de la biometría fetal no coincidían con la edad gestacional; no se presentaron complicaciones médicas o quirúrgicas, a más de una infección de vías urinarias en el primer trimestre, tratada y corregida. Los movimientos fetales se iniciaron a la semana 18, de tipo enérgico. La madre no refiere exposición a teratógenos, consumo de tabaco o alcohol.

El infante fue obtenido por cesárea a las 38 semanas de gestación, debido a distocia de presentación. APGAR 3,6,8. Las medidas al nacimiento fueron las siguientes: peso $3350 \mathrm{~g}$, talla $49 \mathrm{~cm}$ y perímetro cefálico $36 \mathrm{~cm}$, medidas que se encuentran dentro de los percentiles adecuados. El neonato recibió suplementación de oxígeno debido a distrés respiratorio con escala de Silverman 4 (aleteo nasal, retracción xifoidea, tiraje intercostal) y cianosis. Llama la atención las características dismórficas (Figura 1-4).

En el examen físico por regiones, se denotan características dismórficas; en piel la presencia de pliegues e hiperhidrosis, fontanelas amplias, puente nasal plano, narinas en anteversión, filtrum largo, las orejas son de baja implantación, presenta paladar ojival y micrognatia (Figura 1).

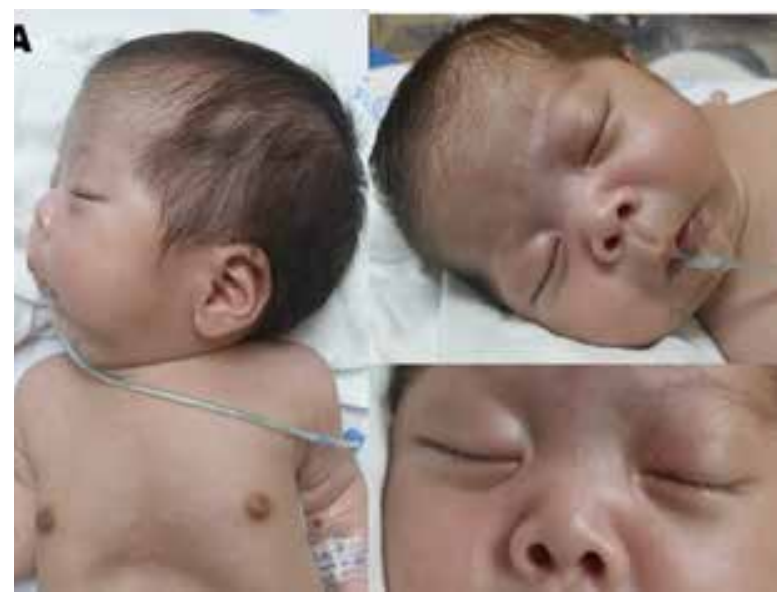

Figura 1. A) Se observa una baja implantación de las orejas y micrognatia. B) La flecha indica el filtrum largo. C) Se observa el puente nasal plano y narinas en anteversión.

Se observa cuello corto, aumento de la distancia entre los pezones conocido como teletelia y pectus excavatum (Figura 2). En las extremidades superiores se evidencia manos con dedos cortos y abotargados en su base, conocido como mano en tridente (Figura 3) y en las inferiores genu varo y espacio aumentado entre el primer y segundo 
dedo del pie, comúnmente conocido como "pie en sandalia" (figura 4), ambas extremidades presentan rizomelia, mesomelia y acromelia.

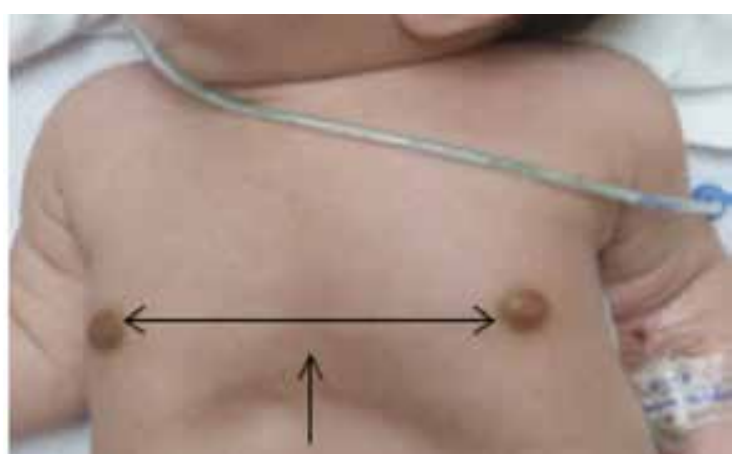

Figura 2. Se observa aumento de la distancia entre los pezones, conocida como teletelia, además de pectus excavatum

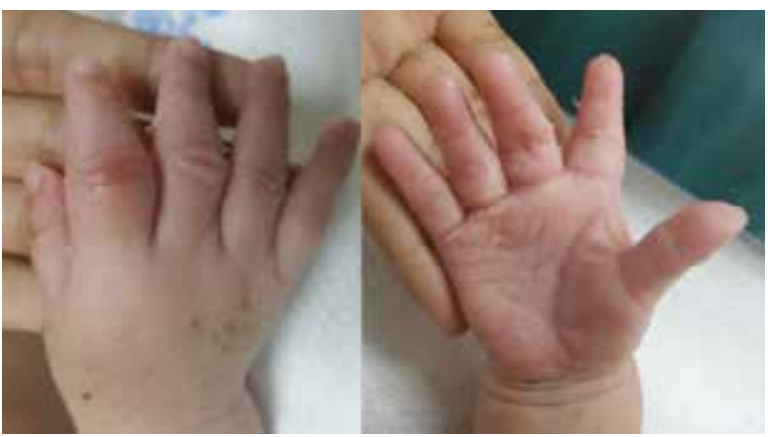

Figura 3. Mano derecha, en la que se observa dedos cortos y abotargados en su base, lo que obliga a sus extremidades a separarse unas de otras, este signo se conoce como "manos en tridente".

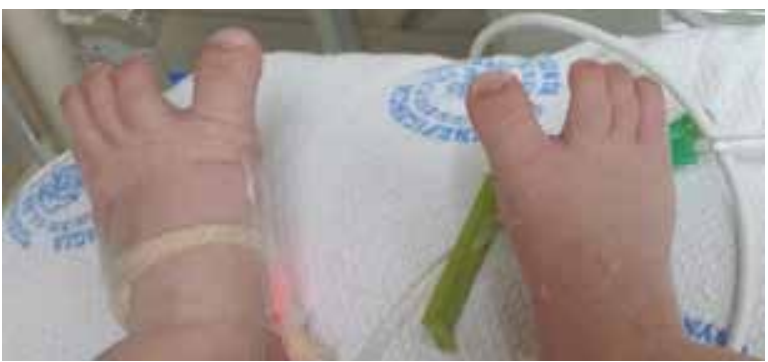

Figura 4. Espacio aumentado entre el primer y segundo dedo del pie, comúnmente conocido como "pie en sandalia"

El examen físico cardiaco, no presenta ruidos agregados y en el pulmonar se evidencia roncus bilaterales y estridor. En el estudio de los antecedentes patológicos familiares en tres generaciones se refiere la muerte del primogénito por inmadurez pulmonar.

En cuanto al examen físico, los parámetros de crecimiento principales se detallan en la en la Tabla 1, y en comparación con los parámetros establecidos por la OMS, en cuanto a peso se encuentra bajo la puntuación $z-2$, lo que indica bajo peso para la edad; la talla se encuentra bajo la puntuación $z-2$, lo que indica retraso en el crecimiento y la circunferencia cefálica que se ha mantenido sin variación evidenciando un retraso en el crecimiento normal.

TABLA 1. PARÁMETROS DE CRECIMIENTO, AL NACIMIENTO Y A LA FECHA DEL EXAMEN FÍSICO

\begin{tabular}{lrr}
\hline & 28 DE NOVIEMBRE /2014 & 9 DE ENERO DE 2015 \\
Peso & $3350 \mathrm{~g}$ & $3664 \mathrm{~g}$ \\
\hline Talla & $49 \mathrm{~cm}$ & $51 \mathrm{~cm}$ \\
\hline Circunferencia cefálica & $36 \mathrm{~cm}$ & $36 \mathrm{~cm}$
\end{tabular}

Los exámenes de laboratorio al ingreso, muestran leucocitosis (12364/ul) a predominio de neutrófilos, hemoglobina elevada $22.7 \mathrm{~g} / \mathrm{dl}$ y plaquetas bajas 79 x 103/ul. Un hemocultivo el 11/Dic presenta cocos Gram +, y una nueva biometría hemática el 24/Dic evidencia normalización en los parámetros.

Se realizó estudio de imágenes: 1) Radiografía portátil de tórax, en la que se observa los bordes de la silueta cardiaca mal delimitados y ensanchamiento de los extremos de los arcos costales de ambos lados (figura 5), 2) Radiografía anteroposterior de extremidades inferiores, en la que se observa acortamiento de ambos fémures, metáfisis femorales distales en forma de campana y configuración en " $V$ " invertida (figura 6), 3) Radiografía anteroposterior de extremidades superiores, en la que se observa desproporción entra la anchura normal y longitud disminuida y acortamiento de los metacarpianos y las falanges proximales y medias (figura 7).

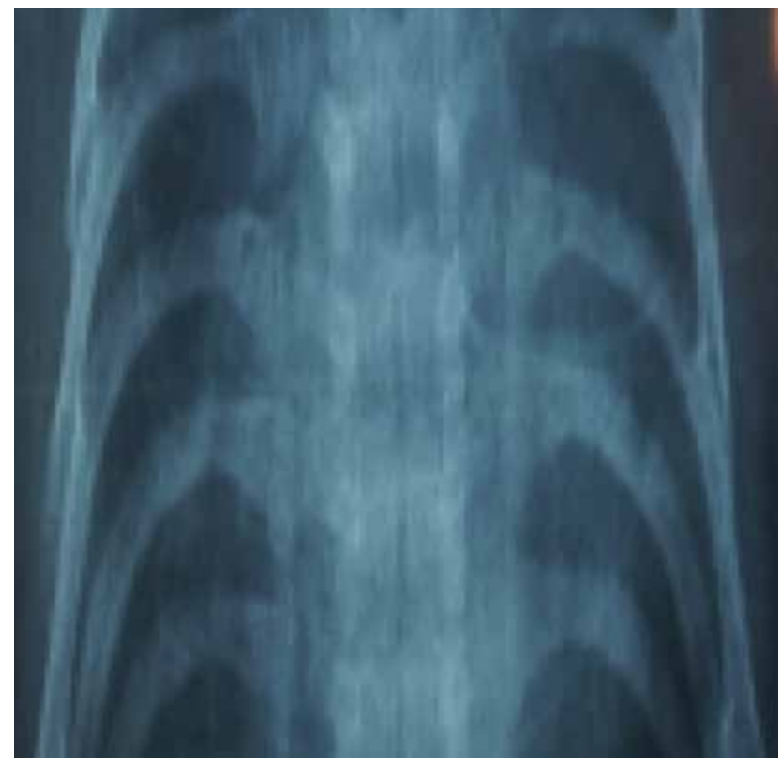

Figura 5. Radiografía portátil de tórax, en la que se observa los bordes de la silueta cardiaca mal delimitados, ángulos costodiafragmáticos libres y ensanchamiento de los extremos de los arcos costales de ambos lados. 


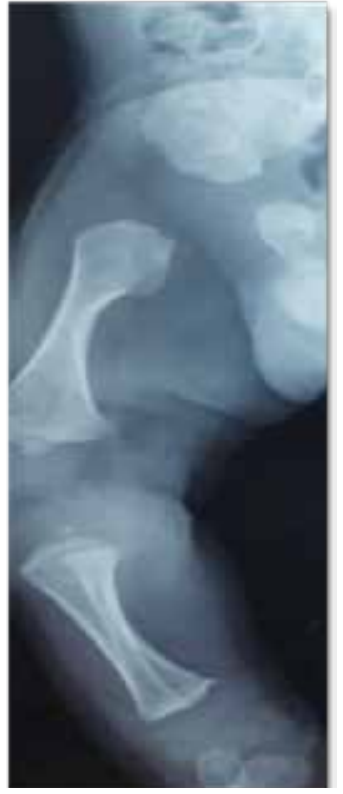

Figura 6. Radiografía anteroposterior de extremidades inferiores, en la que se observa acortamiento de ambos fémures, metáfisis femorales distales en forma de campana y configuración en "V" invertida de las fisis femorales distales, desproporción entra la anchura normal y la longitud disminuida hacen que los huesos tubulares parezcan bastos.

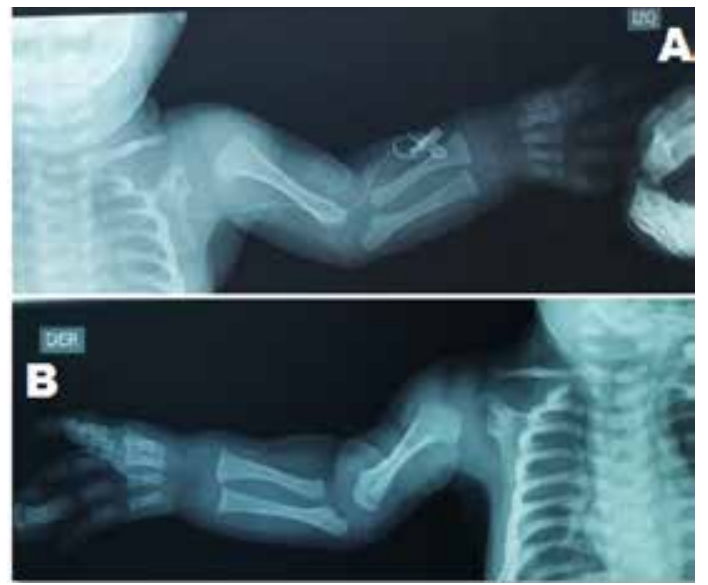

Figura 7. En la imagen $A$ y $B$ se observa una radiografía anteroposterior de extremidades superiores izquierda y derecha, en la que se observa desproporción entra la anchura normal y longitud disminuida y acortamiento de los metacarpianos y las falanges proximales y medias.

Se mantuvo con nutrición parenteral, rotación de esquemas antibióticos y oxigenoterapia, por lo que es trasladado a otra unidad hospitalaria pediátrica para continuar valoración, diagnóstico y tratamiento.

DISCUSIÓN

Displasia ósea es el término asignado a un grupo de patologías de características heterogéneas, cuya principal afectación es observada en la formación y el desarrollo del tejido esquelético, causando en ocasiones severo retardo en el cre- cimiento. ${ }^{6}$ Su etiología ha sido clasificada como extrínseca, cuando se produce por exposición a teratógenos, desórdenes autoinmunes maternos, entre otros; e intrínseca, basada en alteraciones genéticas con herencia autosómica dominante, recesiva o ligada al cromosoma X. ${ }^{2}$ Hasta la actualidad se han descrito aproximadamente 450 tipos de displasias óseas; debido a este gran número, han sido categorizadas en 40 grupos de acuerdo a sus principales características como por ejemplo hallazgos radiológicos, etiología molecular, patrón de herencia, etc. ${ }^{1}$

De acuerdo al orden de frecuencia, la osteocondrodisplasia no letal más frecuente es la acondroplasia, con estadísticas mundiales de 15 a 40 por cada 100,000 recién nacidos mientras que la hipocondroplasia cuenta con 1/12 de la frecuencia de la antes mencionada. $6,7,8$

En la actualidad se busca hacer diagnóstico prenatal de este tipo de patologías a través de métodos ecográficos como mediciones antropométricas y determinación del índice de líquido amniótico, sobre todo en el tercer trimestre, donde se comienza a hacer evidente el acortamiento de extremidades e incremento en diámetro cefálico u abdominal. ${ }^{9}$ Estos hallazgos permiten orientar de manera precoz hacia un tipo de displasia esquelética, siendo las de tipo letal las más fáciles de diagnosticar en estas instancias debido a que suelen ser fenotípicamente más llamativas. ${ }^{2,9}$ Mientras que en la acondroplasia los signos típicos incluyen talla baja, enanismo rizomélico, acortamiento de huesos largos, abombamiento frontal, mano en tridente y fémur arqueado, en el caso de la hipocondroplasia los hallazgos esqueléticos son similares pero en una presentación menos severa (con talla de nacimiento que suele estar dentro del rango normal, acortamiento de extremidades menos marcado, talla final mayor y ausencia de las características faciales de la acondroplasia); ${ }^{7}$ las complicaciones añadidas como apnea obstructiva y estenosis espinal son menos frecuentes, a diferencia de la discapacidad intelectual y epilepsia que suelen tener mayor prevalencia. ${ }^{10}$ En radiología, las características más frecuentes según propusieron Hall y Spranger en el 1979 son la disminución en la distancia interpedicular lumbar, huesos iliacos cortos, huesos largos cortos y gruesos, irregularidad metafisiaria, acortamiento en huesos tubulares de las manos, aumento de longitud en extremo distal de peronés y acortamiento relativo en el extremo distal de cúbitos. ${ }^{11}$ 
El diagnóstico de la hipocondroplasia es difícil en niños por debajo de los 3 años ya que la desproporción esquelética tiende a ser levey las características radiológicas podrían pasar desapercibidas durante los primeros años de la infancia. ${ }^{10,12} \mathrm{El}$ estudio molecular de estos pacientes ha permitido conocer que el $70 \%$ de los individuos afectados son heterocigóticos para las mutaciones p.G380R p.N540k de FGFR37, sin embargo debido a la evidente heterogeneidad del locus, existe un $56,9 \%$ de mutaciones negativas para FGFR 3 que se presume corresponden a mutaciones que aún no han sido dilucidadas por la ciencia, las cuales generarían fenotipos similares, más no idénticos de la enfermedad. ${ }^{10,12,13}$

El caso reportado muestra a un neonato con fenotipo similar a acondroplasia, debido al acortamiento de sus huesos largos, hipoplasia nasal, abombamiento frontal y mano en tridente, sin embargo no encaja de manera exacta en los hallazgos típicos de una acondroplasia, su presentación clínica es menos severa lo cual impidió su diagnóstico prenatal enfocado hacia dicha entidad y hace sospechar en hipocondroplasia, esto sumado a su corta edad, genera dificultad para encasillarlo dentro de un tipo específico de displasia ósea; hace falta un estudio molecular exhaustivo y observar de qué forma evoluciona con el paso de los años, si llegara a presentar problemas de aprendizaje o de talla que permitan definir mejor su diagnóstico. Posee además signos que no son habituales en las osteocondrodisplasias como el espacio aumentado entre el primer y segundo dedo del pie, comúnmente conocido como "pie en sandalia”, muy característico de niños con trisomía $21^{14,15}$ y paladar hendido ojival.

\section{CONCLUSIONES Y RECOMENDACIONES}

Para llegar a un diagnóstico es necesario establecer una vigilancia, mediante radiografías de serie ósea, que brindarán datos característicos e importantes para su estudio y guía para los continuos análisis durante los primeros años de vida y de ser factible, realizar un análisis molecular para llegar a un diagnóstico definitivo.

\section{REFERENCIAS BIBLIOGRÁFICAS}

1. Matthew L. Warman,Valerie Cormier-Daire, Christine Hall,Deborah Krakow, Ralph Lachman, Martine LeMerrer, et al. Nosology and Classification of Genetic Skeletal Disorders: 2010 Revision. Am J Med Genet Part A 155:943-968.

2. Phyllis Glanc, MD, FRCPCDavid Chitayat, MD, FABMG, FACMG, FCCMG, FRCPC. Prenataldiagnosis of thelethal skeletal dysplasias. Literature review current through:
Jan 2015. |This topiclastupdated: Dec 18, 2014. Disponible en: Uptodate

3. J. Rodríguez Delgado, J. Guerrero Fernández, R. Gracia Bouthelier, etal. Hipocondroplasia y retraso mental. An Pediatr(Barc). 2008;68(6):650-65.

4. Hüseyin Anıl Korkmaz, Filiz Hazan, Ceyhun Dizdarer, Ajlan Tükün. Hypochondroplasia in a Child with 1620C>G(Asn540Lys) Mutation in FGFR3. J Clin Res PediatrEn docrinol 2012;4(4):220-222.

5. Geert Mortier, Lieve Nuytinck, Margarita Craen, JeanPierre Renard, et al. Clinical and radiographic features of a family with hypochondroplasia owing to a novel Asn540Ser mutation in the fibroblast growth factor receptor 3 gene. J Med Genet2000;37:220-224.

6. Piana Román. Displasias óseas. El residente, Vol. IV Número 1-2009: 5-9

7. Mancilla, Poggi, Repetto, García, Foradori, Cattani. Mutaciones del gen del receptor 3 del Factor de Crecimiento de Fibroblasto (FGFR3) en pacientes chilenos con talla baja idiopática, hipocondroplasia y acondroplasia. Rev Méd Chile 2003; 131: 1405-1410

8. RichardMPauli, MD, PhD, Achondroplasia. Department of Pediatrics University of Wisconsin ,Madison, Wisconsin ude.csiw.namsiaw@iluap Initial Posting: October 12, 1998; Last Update: February 16, 2012

9. Chitty LS, Griffin DR, Meaney C, Barrett A, Khalil A, PajkrtE, ColeTJ. New aids for the non-invasive prenatal diagnosis of achondroplasia: dysmorphic features, charts of fetal size and molecular confirmation using cell-free DNA in maternal plasma. Ultrasound Obstet Gynecol. 2011;37:283-9. (PubMed)

10. Michael B Bober, MD, PhD, Gary A Bellus, MD, PhD, Sarah M Nikkel, MD, and George E Tiller, MD, PhD. Hypochondroplasia, Initial Posting: July 15, 1999; Last update: September 26, 2013. NCBI

11. Hall BD, Spranger J. Hypochondroplasia: Clinical and Radiological Aspects in 39 Cases. Radiology 1979; 133: 95-100.

12. Bober MB, Taylor M, Heinle R, Mackenzie W. Achondroplasia-hypochondroplasia complexand abnormal pulmonary anatomy. Am J Med Genet A. 2012;158A:2336-41. [PubMed]

13. Song SH, Balce GC, AgasheMV, LeeH, Hong SJ, Park YE, Kim SG, Song HR. New proposed clinico-radiologic and molecular criteria in hypochondroplasia: FGFR 3 gene mutations are not the only cause of hypochondroplasia. Am JMed Genet A. 2012;158A:2456-62. [PubMed]

14. KathrynKOstermaier, Downsyndrome: Clinical features and diagnosis. Literature review current through: Jan 2015. This topic last updated: Jan 20, 2015. Disponible en: Uptodate

15. Dumic, Barisic, Potocki, Sansovic. Hypochondroplasia due to FGFR3 gene mutation (N540K) and mosaic form of Down syndrome in the same patient. J Appl Genetics (2011) 52:209-212 